\title{
Wet-spun bi-component alginate based hydrogel fibers: Development and in-vitro evaluation as a potential moist wound care dressing
}

DOI:

10.1016/j.jijbiomac.2020.12.088

\section{Document Version \\ Accepted author manuscript}

Link to publication record in Manchester Research Explorer

Citation for published version (APA):

Umar, M., Ullah, A., Nawaz, H., Areeb, T., Hashmi, M., Kharaghani, D., Kim, K. O., \& Kim, I. S. (2021). Wet-spun bi-component alginate based hydrogel fibers: Development and in-vitro evaluation as a potential moist wound care dressing. International Journal of Biological Macromolecules, 168, 601-610.

https://doi.org/10.1016/j.ijbiomac.2020.12.088

\section{Published in:}

International Journal of Biological Macromolecules

\section{Citing this paper}

Please note that where the full-text provided on Manchester Research Explorer is the Author Accepted Manuscript or Proof version this may differ from the final Published version. If citing, it is advised that you check and use the publisher's definitive version.

\section{General rights}

Copyright and moral rights for the publications made accessible in the Research Explorer are retained by the authors and/or other copyright owners and it is a condition of accessing publications that users recognise and abide by the legal requirements associated with these rights.

\section{Takedown policy}

If you believe that this document breaches copyright please refer to the University of Manchester's Takedown Procedures [http://man.ac.uk/04Y6Bo] or contact uml.scholarlycommunications@manchester.ac.uk providing relevant details, so we can investigate your claim.

\section{OPEN ACCESS}




\section{International Journal of Biological Macromolecules \\ Wet-Spun Bi-component Alginate Based Hydrogel Fibers: Development and In-vitro Evaluation as a Potential Moist Wound Care Dressing. \\ --Manuscript Draft--}

\begin{tabular}{|c|c|}
\hline Manuscript Number: & IJBIOMAC-D-20-05305R1 \\
\hline Article Type: & Research Paper \\
\hline Section/Category: & Carbohydrates, Natural Polyacids and Lignins \\
\hline Keywords: & $\begin{array}{l}\text { wet spinning } \\
\text { moist wound care } \\
\text { bio-compatibility } \\
\text { hyaluronic acid } \\
\text { sodium alginate }\end{array}$ \\
\hline Corresponding Author: & $\begin{array}{l}\text { Icksoo Kim } \\
\text { Shinshu University } \\
\text { Ueda, Nagano JAPAN }\end{array}$ \\
\hline First Author: & Muhammad Umar, PhD \\
\hline & Hifza Nawaz \\
\hline & Tanzeel Areeb, PhD \\
\hline & Motahira Hashmi, PhD \\
\hline & Davood Kharaghani, PhD \\
\hline & Kyu Oh Kim \\
\hline & Icksoo Kim \\
\hline Abstract: & $\begin{array}{l}\text { In this study, bi-component alginate-hyaluronic acid (AHA) fibers were developed by } \\
\text { using two different routes. In the first method, sodium alginate dope solution was } \\
\text { extruded into a coagulation bath containing } \mathrm{CaCl} 2 \text { and subsequently dip-coated with } \\
\text { hyaluronic acid (HA) whereas, in the second method, hyaluronic acid-containing } \\
\text { sodium alginate dope solution was directly extruded into } \mathrm{CaCl} 2 \text { bath. The resulting } \\
\text { AHA fibers were then dehydrated in } 25-100 \% \mathrm{v} / \mathrm{v} \text { acetone solutions and dried in air. } \\
\text { The fibers were characterized by surface morphology, physicochemical analysis, } \\
\text { mechanical performance, swelling percentage, and total liquid absorption }(\mathrm{g} / \mathrm{g}) \text {, cell } \\
\text { viability, and release behavior. The results showed that AHA fibers produced by the } \\
\text { second method have better mechanical performance, high liquid absorption, and } \\
\text { swelling percentage with a more controlled release of hyaluronic acid. The AHA fibers } \\
\text { showed high biocompatibility toward NIH-3T3 cell line in in-vitro testing, and the } \\
\text { MVTR values ( } 650 \text { - } 800 \mathrm{~g} / \mathrm{m} 2 \text { /day) are in a suitable range for maintaining a moist } \\
\text { wound surface proving to be appropriate for promoting wound healing. }\end{array}$ \\
\hline \multirow[t]{3}{*}{ Suggested Reviewers: } & $\begin{array}{l}\text { Sharjeel Abid, PhD } \\
\text { Senior Researcher, National Textile University } \\
\text { sharjeel.abid@ntu.edu.pk } \\
\text { He is expert in Fiber development. }\end{array}$ \\
\hline & $\begin{array}{l}\text { Usama Humayoun, PhD } \\
\text { Assistant Professor, University of Engineering and Technology } \\
\text { drusama@uet.edu.pk } \\
\text { He is an expert in textile and fibrous structures. }\end{array}$ \\
\hline & $\begin{array}{l}\text { Wei Kai, PhD } \\
\text { Professor, Suzhou University } \\
\text { weikai@suda.edu.cn } \\
\text { He is an expert in textile structures. }\end{array}$ \\
\hline
\end{tabular}


Opposed Reviewers:

Response to Reviewers:

A point to point revision file is attached for the reference. 
The Editor

International Journal of Biological macromolecules

December 02, 2020.

\section{Wet-Spun Bi-component Alginate Based Hydrogel Fibers: Development and In-vitro Evaluation as a Potential Moist Wound Care Dressing.}

Dear,

It is our pleasure to submit the revision of our manuscript titled "Wet-Spun Bi-component Alginate Based Hydrogel Fibers: Development and In-vitro Evaluation as a Potential Moist Wound Care Dressing." to "International Journal of Biological macromolecules." This manuscript contains only original data, which has not been published elsewhere, nor is submitted, in the press, or under consideration simultaneously for publication elsewhere.

All authors fully participated in the preparation of the manuscript and accepted responsibility for the results presented. The authors also declare no conflict of interest.

We welcome the reviewers and editorial comments. As these will improve the quality of our work We tried our best to provide data and answer all the queries of the reviewers in the limited available time and unusual closure and limited accessibility of labs due to COVID 19 pandemic situation. All the possible minor revisions have been addressed.

We hope the work we are submitting meet the Journal's standard and will bring an excellent impact at large.

Thanking you in anticipation.

Regards,

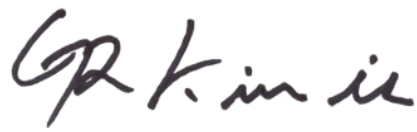

Rising Star Professor, Ick Soo KIM, Dr. Eng.

3-15-1, Tokida, Ueda, Nagano, 386-8567, JA PAN

Tel : +81-268-21-5439, Fax : +81-268-21-5482

E-Mail : kimicksoo@hotmail.com, kim@shinshu-u.ac.jp

https://sites.google.com/site/kimlabgr/Associate

Editor for RSC Advances, Royal Society of Chemistry 


\section{Comments from Editor and Reviewers:}

We welcome the reviewers and editorial comments as these will improve the quality of our work. We tried our best to provide data and answer all the queries of the reviewers in the limited available time and unusual closure and limited accessibility of labs due to the COVID 19 pandemic situation. All the possible major revisions have been addressed.

Note: Responses to the reviewer comments are highlighted in red color in the revised manuscript.

Reviewer \#1:

1. Which sterilization method was applied before cell experiments?

The fiber mats were sterilized with 100\% ethanol for 10 min and dried in the air. Afterward, UV sterilized for $24 \mathrm{~h}$. the sample specimen was not subjected to PBS washing as they dissolve due to ion exchange.

New cell study with nHDF added as per the suggestion of Reviewer 2.

2. The standard error of the control group has to be given in Fig. 8.

Standard errors for control group cannot be added as it was always taken as 100\%.

3. In Figure 9. SEM images are given. The figure captions of $9 \mathrm{a}, 9 \mathrm{~b}, \ldots . ..) \mathrm{g}$ has to be specified. The authors declare that they represent the cell adhesion images on the fibers. However, I could not see cells on the fibers.

Also, magnification values have to be given for each image.

A new cell study with Normal human dermal fibroblast (NHDF) was conducted and added as per the suggestion of Reviewer 2 .

Fig. 9. Caption is revised as per your suggestion.

4. The characteristic peaks of the fibers should be labeled and identified on the FTIR graph. It is revised as per suggestion.

5. Why the FTIR graph of the S7 example is absent?

$\mathrm{S} 7$ is the neat alginate fiber. Caption and legends are changed for clarification.

6. What kind of information we have from the results obtained with the linear density experiment. Why did the authors need the analysis, and which information about the material they had from the analysis? It should be concluded.

Added as per suggestion.

Fiber linear density influence the properties of the products produced from them. Linear density is directly proportional to the air and moisture permeability of the fabric produced from it. The finer the fibers greater will be the surface area and coverage of the fabric. Thus a fabric made of finer fibers will have low MVTR and air permeability and will present better barrier performance than the fabric produce of high linear density. Furthermore, low linear density fibers have greater flexibility, soft and pliable, thus improving the final produced product's comfort. 


\section{Reviewer \#2:}

This paper reports the spinning and characterization of alginate-hyaluronic acid blend fibers using the wet-spinning technique. The as-spun fibers were further made into nonwovens to explore its potential in wound healing. The fibers developed in this work might have a practical application, and the manuscript is well organized and well written. My comments are as follows:

1. The material part of this paper is systematic, but the biological part is too weak to demonstrate the potential application of the fibers. The authors should at least conduct more in vitro assessments, such as cell morphology observations. The selection of cells is also questionable. It is better to use dermal cells for the biocompatibility tests.

A new cell proliferation and cell adhesion study is conducted using nHDF and results are shared.

Cell viability plays an important role in living tissues and thus is an important factor for the tissue engineering and regenerative medicine. To study the cell activity the mitochondrial activity of the nHDF cell on AHA fibers, control alginate and Dimora fibrous mats after 1, 3, and 7 days of culture was investigated by WST-1 assay, as presented in Fig. 8. In metabolically active cells, tetrazolium compound is metabolized to formazan and is secreted into the medium. The resulting change in the medium color was spectrophotometrically measured to reperesent the mitochondrial activity of the viable cells. At all times of inspection the mitochondrial activity of the nHDF cells was higher in the AHA fibers in comparision to the control alginate and the commercial Dimora wound dressing. The difference in the dip coated and dope mixed AHA fibers can be attributed to the fact that the HA release from the dip coated is samples was faster in comparision to the dope mixed samples. Furthermore, as the amount of HA in the fibers increases the cell viability also increased. So, overall we can infer from the results of the WST-1 assay that the addition of HA in the alginate hydrogel fibers improves their biocompatibility.

To determine the morphological differences in the way cells attach to the alginate control and AHA fibrous mats, the cell-cell and cell-material interactions were investigated by SEM. The represented micrographs are shown in Fig. 9. Interestingly the cells were found in a cluster form on the pure alginate fibers and the dip coated AHA fibers (especially with low amount of HA). From the results it is indicated that the cell-cell interaction is stronger on the alginate and low HA containg samples rather than cell material interaction, which results in weakened attachment of $\mathrm{nHDF}$ to the alginate fiber surface and results in agglomeration of the cells.

On AHA fibers produced by dope mixing, more cells were found spreaded acroos the surface of the fibers which indicates that the addition of HA has improved the cell material interaction and allow for the migration of the cells acroos the fibrous mats.

2. Wet-spun alginate fibers have long been commercialized, and I understand this is the reason that hyaluronic acid has been added. However, the comparison between commercial alginate fiber and the fiber developed in this work should be included.

Comparison between AHA fibers and commercial Alginate wound dressing (Dimora) marketed by Winner Medical Co., Ltd., included.

Comparing the liquid absorption of the AHA fibers with the commercially available alginate wound dressing (Dimora), it was found that the PBS $(12.01 \pm 0.62 \mathrm{~g} / \mathrm{g})$ and Sol. A $(6.97 \pm 0.46 \mathrm{~g} / \mathrm{g})$ absorption of the Dimora dressing was similar to the pure alginate (S7) samples. The slight 
difference accounted between S7 and Dimora could be due to the difference in the composition of the alginate used for making these fibers, As S7 and AHA fibers are produce using high guluronic acid content alginate and Dimora is composed of high mannuronic acid content. The composite AHA fibers showed higher liquid absorption both in PBS and Sol.A in comparision to Dimora dressing.

Dimora wound dressing having a similar GSM to the produced nonwoven dressings showed a similar MVTR $(837 \pm 47 \mathrm{~g} / \mathrm{m} 2 /$ day) to S7 pure alginate fibers. The MVTR of all the composite AHA fibers was lower than the Dimora dressing commercially availbale. 


\section{Highlights}

- HA-alginate fibers by dip coating and dope mixing were successfully prepared.

- The inclusion of HA improved the cell viability and proliferation of AHA fibers.

- AHA fiber mats show MVTR of less than $35 \mathrm{~g} / \mathrm{m}^{2} / \mathrm{h}$.

- AHA composite fiber showed absorption of $23 \mathrm{~g} / \mathrm{g}$ in PBS. 


\begin{abstract}
:
In this study, bi-component alginate-hyaluronic acid (AHA) fibers were developed by using two different routes. In the first method, sodium alginate dope solution was extruded into a coagulation bath containing $\mathrm{CaCl}_{2}$ and subsequently dip-coated with hyaluronic acid (HA) whereas, in the second method, hyaluronic acid-containing sodium alginate dope solution was directly extruded into $\mathrm{CaCl}_{2}$ bath. The resulting AHA fibers were then dehydrated in $25-100 \% \mathrm{v} / \mathrm{v}$ acetone solutions and dried in air. The fibers were characterized by surface morphology, physicochemical analysis, mechanical performance, swelling percentage, and total liquid absorption (g/g), cell viability, and release behavior. The results showed that AHA fibers produced by the second method have better mechanical performance, high liquid absorption, and swelling percentage with a more controlled release of hyaluronic acid. The AHA fibers showed high biocompatibility toward NIH-3T3 cell line in in-vitro testing, and the MVTR values $\left(650-800 \mathrm{~g} / \mathrm{m}^{2} / \mathrm{day}\right)$ are in a suitable range for maintaining a moist wound surface proving to be appropriate for promoting wound healing.
\end{abstract}

Keywords: hyaluronic acid; sodium alginate; wet spinning; moist wound care; bio-compatibility 


\section{Wet-Spun Bi-component Alginate Based Hydrogel Fibers: Development and In-vitro Evaluation as a Potential Moist Wound Care Dressing.}

Muhammad Umar ${ }^{\mathrm{a}, \mathrm{b}+}$, Azeem Ullah ${ }^{\mathrm{a}+}$, Hifza Nawaz ${ }^{\mathrm{b}}$, Tanzeel Areeb ${ }^{\mathrm{c}}$, Motahira Hashmi ${ }^{\mathrm{a}}$, Davood Kharaghani ${ }^{\mathrm{d}}$, Kyu Oh Kim ${ }^{\mathrm{e}}$, and Ick Soo Kim ${ }^{\mathrm{a} *}$

a Nano Fusion Technology Research Group, Institute for Fiber Engineering (IFES), Interdisciplinary Cluster for Cutting Edge Research (ICCER), Shinshu University, Tokida 315-1, Ueda, Nagano, Japan. (386-8567)

${ }^{\mathrm{b}}$ Department of Materials, University of Manchester, Manchester, United Kingdom. (M13 9PL)

${ }^{c}$ Department of Bioengineering, Oakland University, Rochester Hill, USA. (MI 48306)

d Department of Calcified Tissue Biology, Graduate School of Biomedical and Health Sciences, Hiroshima University, 1-2-3 Kasumi, Minami-Ku, Hiroshima, Japan. (734-8553)

${ }^{\mathrm{e}}$ Department of Fiber-System Engineering, Dankook University 152, Jookjeon-ro, Suji-gu, Yongin-si, Gyeonggi-do, Republic of Korea. (16890)

+ Authors with equal contribution. Considered as the first authors.

\section{*Corresponding Author:}

Prof. Dr. Ick Soo Kim

Shinshu University, Tokida 3-15-1, Ueda, Nagano, Japan. (386-8567)

E-mail: kim@shinshu-u.ac.jp 


\section{Introduction}

In the modern world, the concept of moist wound healing demands enhancement to increase the level of life, ease of application, and fasten the healing process [1]. The moist wound healing process was introduced by George Winter in 1962, according to his theory, the moist wound heals faster than dry wounds. Many other studies have also been documented, which describes that the wet dressings are beneficial in quality of healing and reducing the time of healing [2]. Maintaining a moist environment of the wound facilitates the healing procedure. The beneficial effects of the humid wound climate are to prevent tissues or cells from death by dehydration and accelerated angiogenesis [3]. The fundamental idea in moist wound healing is that the suitable quantity exudate will provide an environment that stimulates healing by delivering a range of cells and cytokines necessary for wound repair [4]. The dermal tissues exposed in the air become dehydrated, and epidermis migrates under the dehydrated tissue where it can get sufficient moisture to live $[5,6]$. If the surface of the wound is kept moist by using moist wound dressings, the epidermis will quickly migrate towards the surface of the dermis for faster wound healing $[7,8]$.

Polysaccharide based fibers and polymers have amazing applications, including nutrition, therapeutics, and wound dressings [9,10]. Polysaccharides are long-chain carbohydrates consisting of mostly repeated units of monosaccharides, which may or may not be of the same monomer [11]. These polysaccharide-based fibers possess biologically active compounds for the design of biocompatible, biodegradable, and environmentally friendly materials owing to their remarkable molecular structure [12]. In the last twenty years, a lot of research has been done to explore the biological properties of polysaccharides for their utilization in the biomedical field. Polysaccharides exist in the form of plants and animals like psyllium and alginate, which can be extracted [13].

Alginate belongs to a family of polysaccharides obtained from brown algae [14]. Alginic acid was found, produced and patented by Stanford in 1881. It has been used in a variety of sectors, such as food, textile printing, medication, paper industry, and many other novel ends uses. Alginate is a remarkable gel developing content blessed of having a lot of water. In recent times, alginate continues to be used in the wound management industry as a unique material for the development of 'moist healing' items, for example, skin gels, ointments, foams, and also fibrous nonwoven dressings which can be utilized to protect chronic wounds [15]. Alginate exhibits a chain of $(1,4)$ linked $\beta$-D-mannuronic acid (M) and $\alpha$-L-guluronic acid (G) monomers $[16,17]$. These sugar acids are distributed in blocks and have extensively varying 
proportions and sequences. Alginate consists of homopolymeric regions of $\mathrm{M}$ and $\mathrm{G}$, known as $\mathrm{M}$ and $\mathrm{G}$ blocks, which combine as an alternating structure. Typically, the blocks are composed of three different forms of polymer segments: consecutive $\mathrm{G}$ residues, consecutive $\mathrm{M}$ residues, and alternating MG residues resultant hydrogels $[18,19]$.

Hyaluronic acid (HA) is a linear polysaccharide sourced from nature. The macromolecule consists of $\mathrm{N}$-acetyl glucosamine as well as glucuronic acid solution. It is composed of alternating disaccharide units of a-1,4-D-glucuronic acid and b-1,3-N-acetyl-D-glucosamine [20]. Its molecular weight varies from 103 to 107 . HA is a glycosaminoglycan discovered in conjunctive cells of almost any vertebrate. This polyanionic polymer is also found in connective tissues, including umbilical cord, synovial fluid, vitreous, etc. [21]. HA has been largely applied in the fields of controlled medication delivery, cellular encapsulation, and muscle regeneration due to its exclusive viscoelastic properties and excellent biocompatibility [22]. Being an extracellular matrix component, HA may impact several cellular characteristics such as attachment, migration, as well as growth. The latest biomedical applications of HA include things like scaffolds pertaining to wound therapeutics as well as cell technological innovation, and surgery therapy, osteoarthritis cure, in addition to being a part of implant materials $[23,24]$.

Hussain et al. developed alginate/chitosan/hyaluronic acid ( $\mathrm{ACH})$ composite fibers by wet spinning and subsequent coating procedures. Sodium alginate was extruded into a calcium chloride bath to produce calcium alginate fibers and then passed through hydrolyzed chitosan bath and dip-coated in HA to develop new fibers. The inclusion of HA increases the swelling and absorption properties of fibers. The addition of hydrolyzed chitosan and HA also improves the tensile properties of fibers. Newly developed fibers have shown a controlled release of HA and found useful applications in wound care [19]. Yamane et al. developed chitosan polymer fibers and chitosan-based HA hybrid polymer fibers by wet spinning technique. The novel fiber of chitosan-based HA comprised of chitosan-coated HA $(0.04 \%$ and $0.07 \%)$. These can be useful as a scaffold biomaterial for cartilage tissue engineering. It has been found that composite fibers have more cell adhesivity, proliferation, and the synthesis of cartilage-specific proteoglycan core protein (aggrecan) than in the chitosan fiber. The chitosan-based hyaluronic acid hybrid polymer fibers demonstrate excellent prospects as a suitable biomaterial for cartilaginous tissue scaffolds [25]. Maeda et al. manufactured chitosan-hyaluronic acid hybrid polysaccharide fibers by electrospinning of polycationic chitosan with PEO and then coated them by polyanionic hyaluronic acid. Chitosan-hyaluronic acid fibers remained stable in water, 
although they show a controlled release of HA in phosphate-buffered saline solution (PBS). The swelling ratio of newly developed nanofibers was increased by $30 \%$ on coating of $3-w t \%$ hyaluronic acid. Newly developed chitosan-hyaluronic acid fibers have significant contribution in faster wound healing and controlled drug delivery along with other biomedical applications [26]. Yamane et al. developed three-dimensional scaffolds designed from the composite chitosan-based HA polymer fibers. The wet spinning technique was used to manufacture chitosan-based HA composite polymer fibers, followed by the coating of HA $(0.07 \%)$. The tensile strength, diameter, and tension at fracture of the composite polymer fiber were $144.4 \mathrm{~N} / \mathrm{mm}^{2}, 0.03 \mathrm{~mm}$, and $9.7 \%$, respectively [27].

The present research work deals with the development and characterization of alginatehyaluronic acid (AHA) fibers for moist wound management. It is quite challenging to achieve properties like high tenacity, swelling, absorption, and controlled release by the coating of HA on alginate fiber. It is also challenging to fabricate pure HA fibers due to its high viscosity; therefore, alginate and HA are combined to prepare a dope solution and then converted into fibers. The fibers developed by both coatings of HA on alginate fiber and mixing of HA in alginate dope to fabricate a bi-component fiber were characterized for surface morphology, physicochemical analysis, in vitro biocompatibility, release behavior, swelling and fluid absorption properties.

\section{Experimental}

\subsection{Materials}

Hyaluronic acid was purchased from Sigma Aldrich, Czech Republic. Fiber grade Sodium Alginate (Portnal L/F 10/60), with high guluronic acid content (65-75\%), was purchased from FMC Biopolymer, Norway. Calcium chloride $(\mathrm{CaCl} 2)$ and Acetone $(99 \%)$ of analytical grade were purchased from RDH laboratories $\mathrm{GmbH} \&$ Co., and Merck, respectively. Laboratory grade sodium chloride $(\mathrm{NaCl})$, acetic acid $100 \%$, and hydrochloric acids $(\mathrm{HCl}) 37 \%$ were purchased from UNICHEM chemical reagents.

\subsection{Fiber Production}

Spinning solutions of sodium alginate and HA were prepared in double-distilled water. The dope solution was mechanically stirred overnight to ensure solution homogeneity and was allowed to stand still afterward to degas them. Fig.1 shows the two fiber production routes employed: first, the alginate dope was extruded into $\mathrm{CaCl}_{2}(1.5 \% \mathrm{w} / \mathrm{v})$ at a constant draw ration 
of 5. The fibers were then washed in distilled water and then dehydrated stepwise in acetone solution at different ratios $25 \%, 50 \%, 75 \%$, and $100 \%$, respectively. The fibers were then airdried before dipping in HA solution $(0.25 \%, 0.5 \%$, and $1 \% \mathrm{w} / \mathrm{v})$ for $24 \mathrm{~h}$. The dip-coated fibers were again dehydrated using acetone solution stepwise. In the second route, the dope solution of alginate and $\mathrm{HA}$ was extruded directly into the $\mathrm{CaCl}_{2}$ solution using the same parameter as in the first route. Table 1 shows the experimental design for AHA composite fibers production.

The AHA composite fibers and control alginate fibers were converted into nonwoven sheets using a lab-scale carding machine (Shirley + miniature spinning plant, UK), to perform specific characterization like cell study and moisture vapor transmission rate analysis. The final weight of the produced nonwoven sheets was $\sim 200 \mathrm{~g} / \mathrm{m}^{2}$. The nonwoven sheets were only consolidate using cold calendar rollers to cause minimum change to the morphology of the as-spun fibers.

\subsection{Characterization of fibers}

\subsubsection{Scanning electron microscopy}

The scanning electron microscopy (SEM, JSM-6010LA, JEOL, Japan) was used to study the surface morphology of the produced fibers. The fibers were sputtered coated with platinum before SEM photographs were taken.

\subsubsection{Physicochemical analysis}

The produced AHA fibers were subjected to Fourier transform infrared (FTIR) spectroscopy for physicochemical analysis using Prestige-21, Shimadzu Co, Ltd., Japan, with a range of $4000-400 \mathrm{~cm}^{-1}$ wavenumber.

\subsubsection{Fiber linear density}

After conditioning all the fiber samples at standard atmospheric conditions, the linear density of the fibers was determined according to ASTM D 1059-12. Forty specimens of 2-inch length from each fiber sample were prepared and weighed, using an analytical balance. The length was converted into meters. The linear density in "tex" was calculated by using Eq 1. Finally, the mean value of the linear density of each fiber sample was determined along with the standard deviation.

$$
\text { tex }=\frac{\text { weight in grams }(\mathrm{g})}{1000 \mathrm{~m}}
$$




\subsubsection{Tensile properties}

The tensile properties of the fibers were measured by using a single fiber strength testing system, M250-2.5CT (Testometric, Rochdale, England). The test method employed was BS EN ISO 5079. The machine works on the principle of a constant rate of extension (CRE). A single fiber was clamped between two points, one moveable and one fixed, $10 \mathrm{~mm}$ apart, and force applied was $10.0 \mathrm{~N}$ and set at $12 \mathrm{~mm} / \mathrm{min}$ constant rate of extension. The average value of ten specimens from each fiber sample was taken.

\subsubsection{Liquid absorption}

Liquid absorption properties of all the developed fibers were tested using three different liquids, i.e. deionized water, saline $(0.9 \% \mathrm{w} / \mathrm{v} \mathrm{NaCl})$ and solution $\mathrm{A}(0.8298 \% \mathrm{w} / \mathrm{v} \mathrm{NaCl}$ and $0.0368 \% \mathrm{w} / \mathrm{v} \mathrm{CaCl} 2$ ). All samples were initially soaked for 1 hour and hung in the air until no liquid droplet fell prior to taking wet weight measurements. Liquid absorption was calculated as the ratio of the wet weight of the fibers to the weight of the fiber after drying overnight at $105^{\circ} \mathrm{C}$. Absorption was calculated by using the Eq 2:

$$
\operatorname{Absorption}(\mathrm{g} / \mathrm{g})=\frac{\mathrm{Ww}-\mathrm{Wd}}{\mathrm{Wd}}
$$

Where $\mathrm{W}_{\mathrm{d}}$ refers to the dry weight of fiber, and $\mathrm{W}_{\mathrm{w}}$ is the wet weight of fiber[17].

\subsubsection{Swelling behavior}

Swelling behavior or change in fiber diameter of the produced fiber was observed by using a MICROS optical microscope (MC-50) with a digital camera. The change in diameter of the fibers was noted after soaking (for 4 minutes) in the above-mentioned solutions at $25^{\circ} \mathrm{C}$. Eq 3 can be used to calculate $\%$ swelling of fibers:

$$
\% \text { swelling }=\frac{\mathrm{Dw}-\mathrm{Dd} \times 100}{\mathrm{Dd}}
$$

Where Dw is the wet fiber diameter, and Dd is dry fiber diameter [17].

\subsubsection{Release study of hyaluronic acid}

The release profile of HA was checked by using a UV-Vis spectrophotometer. In this process, firstly standard absorption curve was developed at $600 \mathrm{~nm}$ for HA at different concentrations. A quadratic equation was developed from the standard absorption curve. Fig. 2 shows the standard absorption curve and the quadratic equation. 
The amount of turbidity developed on the addition of cetyltrimethylammonium bromide $(\mathrm{CTAB})$ into acetate buffer and specimen is proportional to the amount of HA present in solution. Acetate buffer includes $0.2 \mathrm{M}$ sodium acetate-acetic acid and $0.15 \mathrm{M} \mathrm{NaCl}$ of $\mathrm{PH} 6$. $\mathrm{CTAB}$ reagent includes cetyltrimethylammonium bromide $(2.5 \mathrm{gm})$ in 2 percent of $100 \mathrm{ml}$ $\mathrm{NaOH}$. These two solutions were incubated at $37^{\circ} \mathrm{C}$ in order to synchronize the reaction temperature $[19,28,29]$.

The developed fibers were placed separately in PBS and solution A. After 2 hours, $1 \mathrm{ml}$ of the specimen was taken from solutions into test tubes, then $1 \mathrm{ml}$ of acetate buffer and $2 \mathrm{ml}$ of CTAB reagent was added in the same tubes. After mixing, the contents of test tubes were transferred to cuvettes, and absorption was checked at a wavelength of 600nm [28]. The absorption values taken by UV/VIS spectrophotometer were placed in the quadratic equation (based on standard absorption curve) to calculate the release of HA in $\mathrm{mg} / \mathrm{liter}$ (ppm).

\subsubsection{In-vitro Cell Proliferation}

According to ISO 10993-5 standards, the effect of AHA fibers on the viability of normal human dermal fibroblast (nHDF) cell line Briefly, nHDF cell were cultured in Dulbeco modified eagle medium (DMEM) accompanying 10\% fetal bovine serum (FBS) in a humidified incubator at $37^{\circ} \mathrm{C}$ and $5 \% \mathrm{CO}_{2}$ environment. The fiber mats were sterilized with $100 \%$ ethanol for $10 \mathrm{~min}$ and dried in vaccum chamber at ambient temperature, and afterward UV sterilized for $24 \mathrm{~h}$. The sample speciemen were not subjected to PBS washing as they will dissolve due to ion exchange. The sterilized AHA fibers were placed in 96 well glass culture plates. The fiber-free cells were used as controls. The well was seeded with $1 \times 10^{4}$ cells per well. The well was

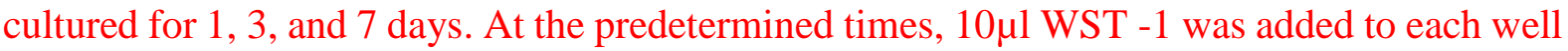
and incubated for two hours. Absorbance was measured at $440 \mathrm{~nm}$ using a microplate reader (Thermos Scientific, Multiskan FC instruments) as an indicator for proliferation. Readings were measured in triplicate, and averages were recorded.

\subsubsection{Cell adhesion}

The nHDF cell attachment on the control alginate and AHA fibrous mats were observed with SEM micrographs. nHDF cells after $48 \mathrm{~h}$ of culture were fixed on the mats with $4 \%$ paraformaldehyde for $4 \mathrm{~h}$ at $4^{\circ} \mathrm{C}$. The mats were dehydrated using ethanol. The mats were vacuum dried before SEM imagery. The resolution for SEM micrographs was $\mathrm{x} 100$ for all samples. 


\subsubsection{Moisture Vapor Transport Rate (MVTR)}

To evaluate the MVTR of the produced composite AHA fibers, the fibers were converted into nonwoven sheets using a lab-scale carding machine (Shirley + miniature spinning plant, UK) and afterward consolidated using cold calendar rollers at 2 bar pressure. The nonwoven webs were cut into $9 \mathrm{~cm}$ diameter and placed over a cup with $7 \mathrm{~cm}$ diameter. The containers were filled with water up to three-quarter level and weighed "W". The cups were placed in an incubator under $40 \%$ humidity at $37^{\circ} \mathrm{C}$. The cups were removed from the incubator after 24 hours and weighed again "W". MVTR was calculated from the following Eq. 4.

$$
\operatorname{MVTR}=G / A t
$$

Where " $G$ " is the weight change $\left(\mathrm{W}_{1}-\mathrm{W}_{2}\right)$, " $\mathrm{A}$ " is the area of the cup mouth, and " $\mathrm{t}$ " is the time in which "G" happened.

\subsubsection{Comparison with a commercial Alginate dressing}

The produced AHA fibers were compared against commercially available Dimora (Alginate Wound Dressing) marketed by Winner Medical Co., Ltd. The produced fibers were compared for MVTR, liquid absorption (g/g), and cell proliferation. The commercial alginate dressing was composed of high mannuronic acid content $50-70 \%$, the GSM of the commercial dressing was $\sim 192 \mathrm{~g} / \mathrm{m}^{2}$, which is close to our produced nonwoven dressing.

\subsubsection{Statistical Analysis}

One-way analysis of variance (ANOVA) to indicate the statistical significance of the results was performed using the MINITAB-17 $®$ software package.

\section{Results and Discussion}

The statistical significance of the different concentrations of the HA on the response variables was conducted by one-way ANOVA. Table 2 gives details of the analysis. P-value (probability of null hypothesis $) \leq 0.05$ indicates the statistical significance of the effect [30,31]. It is evident from Table 2 that the impact of HA concentration has a statistically significant impact on most of the responses under study, i.e., linear density, tenacity, swelling, and absorption capacity.

\subsection{Surface morphology}

The representative S.E.M. micrographs of the composite AHA and the control fibers are given in Fig. 3. Despite the smooth rounded holes of the spinneret, the produced fibers are partially 
flattened like ribbon. All fibers are characterized by surface striation. These striations were formed by the formation of an egg-box structure in the guluronic constituent of the sodium alginate and the chelating structure built by the HA upon interaction with the calcium ion in the coagulation bath. These striations are dominant in fibers produced by the second route and the control fibers. But in the fibers created by the first route have diminished striation due to the HA coating after the fibers were produced and can be seen in Fig. 3 (a', b', c', d', e', f', and g'). The surface morphology of the materials is very useful in determining their end application. Fibers with uniform and smooth surfaces provide a very soft feel, whereas fibers with striation and non-uniform surfaces provide a very harsh feel.

\subsection{Physicochemical analysis}

Fig. 4 shows the ATR-FTIR spectra of the sodium alginate (S7) and HA powder along with the prepared AHA composite fibers. The alginate spectra showed a few significant intense peaks. $\mathrm{O}-\mathrm{H}$ stretching vibrations were seen in the range of $3400-3200 \mathrm{~cm}^{-1}$, aliphatic $\mathrm{C}-\mathrm{H}$ stretching was observed $2938 \mathrm{~cm}^{-1}$. COO. - asymmetric and symmetric $(\mathrm{C}=\mathrm{O})$ stretching were at wavenumber $1640 \mathrm{~cm}^{-1}$, and $1437 \mathrm{~cm}^{-1}$. At $1324 \mathrm{~cm}^{-1}, \mathrm{C}-\mathrm{O}$ stretching vibration was recorded. The strong peaks between $1100-950 \mathrm{~cm}^{-1}$ are attributed to $\mathrm{C}-\mathrm{O}, \mathrm{C}-\mathrm{C}$, and $\mathrm{C}-$ $\mathrm{O}-\mathrm{C}$ vibrational stretching's [32].

In HA ATR-FTIR spectra, the $-\mathrm{OH}$ and $-\mathrm{NH}$ group vibrational peak was at $3453 \mathrm{~cm}^{-1}$. C$\mathrm{H}$ band stretching was observed at $2925 \mathrm{~cm}^{-1}$. Two distinct peaks at $1710 \mathrm{~cm}^{-1}$ and $1648 \mathrm{~cm}^{-1}$ corresponds to amide and carbonyl groups. The band at $1427 \mathrm{~cm}^{-1}$ represents COOvibrational stretch, which refers to the acid group of HA [33]. The absorption bands at 1139 $\mathrm{cm}^{-1}$ and $1043 \mathrm{~cm}^{-1}$ are attributed to ether $\mathrm{C}-\mathrm{O}-\mathrm{C}$ linkages in the polymer chain [34].

The ATR-FTIR fingerprints of the two polymers understudy, SA, and HA are quite similar to each other; that is why it is challenging to find a peak different from each other in the FTIR spectrum of the produced composite fibers. The only difference observed was in the absorbance peak of the - $\mathrm{OH}$ group, which appears to be shrunken due to the participation of the hydroxyl and carboxylate groups of the polymers in forming a chelating structure with the calcium ions in the coagulating bath [32]. The peak observed in the FTIR fingerprints is in according to the previously reported literature. 


\subsection{Linear Density and Tensile Properties}

The results of linear density and tenacity of all fibers produced by two different methods are shown in Fig. 5. The results show (Fig. 5 (a)) that the addition of HA increases the fibers' linear density developed by the dip-coating method. This may be due to the coating of hyaluronic acid. But the fibers produced by using HA in dope solution have significantly reduced linear density. The reason could be due to the increase in the dope solution's viscosity upon the addition of HA (Table 1). As a result of increased viscosity, the drag (draft) on the dope solution increases while exiting the spinneret's orifice. Thus the resulting fibers are finer than the fibers produced by the dip-coating method. Fiber linear density influence the properties of the products produced from them. Linear density is directly proportional to the air and moisture permeability of the fabric produced from it. The finer the fibers greater will be the surface area and coverage of the fabric. Thus a fabric made of finer fibers will have low MVTR and air permeability and will present better barrier performance than the fabric produce of high linear density. Furthermore, low linear density fibers have greater flexibility, soft and pliable, thus improving the final produced product's comfort.

The tenacity of AHA composite fibers improves on the addition of hyaluronic acid, and it increases with an increase in concentration in Fig. 5 (b). It may be due to alginate and hyaluronic acid's similar properties, which makes them compatible with each other. The chemical resemblance of HA with alginate results in strong interaction among them and thus increases the fiber's strength. It can also be due to the interaction of cationic calcium ions with anionic HA to form calcium hyaluronate [35], which increases the tenacity of the developed fiber. The fibers produced by method B have even higher tenacity than the fiber produced by method A. It can be due to the fact that after mixing alginate and hyaluronic acid, the homogenous dope solution was extruded in a coagulation bath, and fibers were drawn during the manufacturing process. Due to the combined drawing of alginate and HA dope solution, the crystallinity of the fibers increases, and fibers produced are finer and have a more aligned and linear structure, which helps to improve the tenacity of fibers.

\subsection{Swelling and Absorption Properties}

Fig. 6 (a) indicates that the swelling of AHA fibers increases on increasing the concentration of HA at a constant drawing ratio. This seems to be due to the increasing number of hydroxyl and carboxylic groups by adding HA in the developed fiber, which improves the hydrophilic characteristics and thus increases the fiber swelling [36]. 
The fibers produced by the coating method do not show a marked difference from the control alginate fiber (S7), this may be due to the removal of the HA from the surface of the composite fibers upon ion exchange with the respective liquid under study.

In fibers produced by the second route, the overall trend of swelling behavior (\%) is the greatest for PBS solution with a value of $476 \%$. It may be due to the formation of sodium hyaluronate, which is more soluble in water. It can also be due to more ions exchange property (calcium ions exchange by sodium ions) in PBS solution and then solution A. Still, in Solution A, swelling is relatively lower than the saline solution (250\%); this may be due to the presence of calcium ions, which also form calcium hyaluronate, which reduces solubility in water [37]. The presence of calcium also creates a hindrance in ions exchange.

High exudate absorption is a crucial aspect of wound dressing made, especially for moist wound care applications. Wound dressing ensures that the wound surface remains moist, aiding the autolytic debridement and movement of cells across the wound bed during reepithelialization without damaging the surrounding skin by exudate over saturation. Liquid absorption $(\mathrm{g} / \mathrm{g})$ properties in various liquids of the developed AHA fibers is shown in Fig. 6(b). The addition of HA increases the liquid absorption of developed fibers due to its excellent gel-forming properties. Absorbance properties of the composite AHA fiber improved as the amount of HA increased in both sets of composite fibers produced. The newly developed fibers show less absorption in solution A as compared to PBS, it may be due to the presence of calcium ions in it, which creates further hindrance in ion exchange. Most of the absorption in saline and solution A is due to the coating of hydrophilic hyaluronic acid.

Comparing the liquid absorption of the AHA fibers with the commercially available alginate wound dressing (Dimora), it was found that the PBS $(12.01 \pm 0.62 \mathrm{~g} / \mathrm{g})$ and Sol. A $(6.97 \pm 0.46$ $\mathrm{g} / \mathrm{g}$ ) absorption of the Dimora dressing was similar to the pure alginate (S7) samples. The slight difference accounted between S7 and Dimora could be due to the difference in the composition of the alginate used for making these fibers, As S7 and AHA fibers are produce using high guluronic acid content alginate and Dimora is composed of high mannuronic acid content. The composite AHA fibers showed higher liquid absorption both in PBS and Sol.A in comparision to Dimora dressing.

Accordingly, the statistical significance of the HA (p-value 0.000 and 0.003 for swelling, and 0.000 and 0.000 for absorption) indicates that the addition of HA to the alginate fibers had 
significantly improved its liquid retention properties as compared to control alginate fibers (S7).

\subsection{Release study}

The release of HA from the composite AHA fiber after $2 \mathrm{~h}$ of dipping time was studied. According to the results in Fig. 7, it is evident that the release of HA increases on increasing the concentration of hyaluronic acid. It can be due to the higher quantity of HA attached to the fiber.

Overall the trend of the release of HA is maximum in saline solution. It can be due to sodium hyaluronate formation, which is more soluble in water [37]. It can also be due to more ions exchange property (calcium ions exchange by sodium ions) in saline solution. But in Solution A, the release of HA is the lowest. This may be due to the presence of calcium ions, which form calcium hyaluronate, which reduces solubility in water [37]. The presence of calcium in solution A also creates a hindrance in ions exchange.

The release in two sets of composite fibers was quite distinct. In dip-coated fibers, the release was abrupt, which can be attributed to the fact that the HA was coated on the surface, and the ion exchange between the HA and the liquid was effortless without any hindrance thus the release was abrupt. While in dope mixed AHA fibers, the release was slow as compared to the dip-coated fiber set. The reason for this could be the complex chelating structure formed by the alginate and HA upon interaction with the calcium ions in the coagulation bath.

\subsection{Cell viability and adhesion}

Cell viability plays an important role in living tissues and thus is an important factor for the tissue engineering and regenerative medicine. To study the cell activity the mitochondrial activity of the nHDF cell on AHA fibers, control alginate and Dimora fibrous mats after 1, 3, and 7 days of culture was investigated by WST-1 assay, as presented in Fig. 8. In metabolically active cells, tetrazolium compound is metabolized to formazan and is secreted into the medium. The resulting change in the medium color was spectrophotometrically measured to reperesent the mitochondrial activity of the viable cells. At all times of inspection the mitochondrial activity of the nHDF cells was higher in the AHA fibers in comparision to the control alginate and the commercial Dimora wound dressing. The difference in the dip coated and dope mixed AHA fibers can be attributed to the fact that the HA release from the dip coated is samples was faster in comparision to the dope mixed samples. Furthermore, as the amount of HA in the 
fibers increases the cell viability also increased. So, overall we can infer from the results of the

\section{biocompatibility.}

To determine the morphological differences in the way cells attach to the alginate control and AHA fibrous mats, the cell-cell and cell-material interactions were investigated by SEM. The represented micrographs are shown in Fig. 9. Interestingly the cells were found in a cluster form on the pure alginate fibers and the dip coated AHA fibers (especially with low amount of HA). From the results it is indicated that the cell-cell interaction is stronger on the alginate and low HA containg samples rather than cell material interaction, which results in weakened attachment of nHDF to the alginate fiber surface and results in agglomeration of the cells. A similar result has been previously reported [38].

On AHA fibers produced by dope mixing, more cells were found spreaded acroos the surface of the fibers which indicates that the addition of HA has improved the cell material interaction and allow for the migration of the cells acroos the fibrous mats.

\subsection{MVTR Analysis}

In 1962, G. D. Winter found out that scab formed on the surface of the wound contains a superficial part of the dermis, which due to the dehydration of the dermis. He suggested that if the surface of the injury is deliberately kept moist, then the scab formation can be prevented. This would, in turn, help in an increased rate of re-epithelialization [3]. Wound dressings with low MVTR are considered to be able to maintain a moist wound environment. A higher MVTR value will dehydrate the wound and may result in scar formation. Healthy human skin has a trans-epidermal water loss of $4-9 \mathrm{~g} / \mathrm{m}^{2} / \mathrm{h}$. In a full-thickness wound, the water loss increases up to $80-90 \mathrm{~g} / \mathrm{m}^{2} / \mathrm{h}$. Dressings that have an MVTR of less than $35 \mathrm{~g} / \mathrm{m}^{2} / \mathrm{h}$ are considered to be moisture-retentive $[39,40]$. Dressing that retains the tissue fluid help retains the cellular and extracellular components of the wound healing that naturally support the healing process. The MVTR depends not only on the density of the produced nonwoven but also on the absorption properties of the materials. A lower density leads to a higher MVTR, and similarly, a higher absorption leads to a lower MVTR. The density of nonwoven mats was kept constant at 200 $\mathrm{g} / \mathrm{m}^{2}$. The MVTR analysis of the control (S7) and composite AHA fibers are given in Fig. 10. The control alginate fiber (S7) shows an MVTR of $885 \mathrm{~g} / \mathrm{m}^{2} /$ day. The inclusion of HA to the alginate fibers helps increase the moisture absorption of the composite fiber and hence resulted in a decrease in the MVTR of the composite AHA fibers. In both sets of fibers as the HA 
content increases, the MVTR decreases further with the fiber S1, S2, and S3 show an MVTR of 796,736 , and $700 \mathrm{~g} / \mathrm{m}^{2} /$ day. Similarly, the fibers S4, S5, and S6 show an MVTR of 722, 693 , and $667 \mathrm{~g} / \mathrm{m}^{2} / \mathrm{day}$. The MVTR values of the two sets of composite fibers (S1, S2, S3) and (S4, S5, S6) along with the control alginate fibers (S7) are in the acceptable range of value as reported in the literature. Dimora wound dressing having a similar GSM to the produced nonwoven dressings showed a similar MVTR $\left(837 \pm 47 \mathrm{~g} / \mathrm{m}^{2} /\right.$ day $)$ to $\mathrm{S} 7$ pure alginate fibers. The MVTR of all the composite AHA fibers was lower than the Dimora dressing commercially availbale.

\section{Conclusion}

The current work utilized two routes to produce composite AHA fibers. AHA composite fibers were successfully developed by wet spinning and subsequent coating techniques. The fiber surface has distinct surface striations due to the egg box and chelating structure formed by alginate and HA constituents upon interaction with calcium ions in the coagulation bath. The FTIR spectra of alginate and HA were very similar so no significant difference can be observed in the spectra of the composite AHA fibers except the - $\mathrm{OH}$ group, which appears to be shrunken due to participation of the hydroxyl and carboxylate groups of the polymers in forming a chelating structure with the calcium ions in the coagulating bath. The addition of HA resulted in increased tensile strength due to strong interaction between anionic HA and cationic calcium ions. Composite fiber swelling and absorption $(\mathrm{g} / \mathrm{g})$ properties are markedly improved upon the addition of HA with maximum swelling of $476 \%$ and absorption of $23 \mathrm{~g} / \mathrm{g}$ in PBS. The release of HA from the composite fiber was very different in two sets of fibers. In dipcoated fibers, the release was abrupt while in dope mixed fibers, the release was slow, this difference is due to the strong interaction of HA with calcium ions in the dope mixed AHA fibers. MVTR values $\left(650-800 \mathrm{~g} / \mathrm{m}^{2} /\right.$ day $)$ of the composite AHA fibers are in the acceptable range for moist wound care. Cell viability and adhesion study indicates that the addition of HA in the alginate fibers has improved it overall biocompatibility and cell material interaction. Based on the results the fiber produced by dope mixing method have shown an overall better performance.

The developed fibers have low mechanical strengths and can only be produced into nonwoven structures. These fibers can be used only for treating exuding wounds as moisture is one of the significant components for their practical use. 


\section{Funding}

This research did not receive any specific grant from funding agencies in the public, commercial, or not-for-profit sectors.

\section{Declaration of Interest}

None 


\section{References}

[1] S. Guo, L.A. Dipietro, Factors Affecting Wound Healing, J. Dent. Res. 89 (2010) 219229. https://doi.org/10.1177/0022034509359125.

[2] C.K. Field, M.D. Kerstein, Overview of wound healing in moist environment, Am. J. Surg. 167 (1994) 2-6.

[3] G.D. Winter, J.T. Scales, Effect of Air drying and Dressings on the Surface of a Wound, Nature. 4862 (1963) 91-92.

[4] W.H. Eaglstein, Moist Wound Healing with Occlusive Dressings : A Clinical Focus, Dermatologic Surg. 27 (2001) 175-181.

[5] P.J. Van Winterswijk, E. Nout, Tissue Engineering and Wound Healing : An Overview of the Past, Present, and Future, Wounds. 19 (2007) 277-284.

[6] C. Hinman, H. Maibach, Effect of air exposure and occlusion on experimental human skin wounds, Nature. 200 (1963) 377-379.

[7] C. Daunton, S. Kothari, L. Smith, D. Steele, A history of materials and practices for wound management, 20 (2012).

[8] G. Broughton, J.E. Janis, C.E. Attinger, A brief history of wound care., Plast. Reconstr. Surg. 117 (2006) 6S-11S.

https://doi.org/10.1097/01.prs.0000225429.76355.dd.

[9] A. Ullah, S. Ullah, M.Q. Khan, M. Hashmi, P.D. Nam, Y. Kato, Y. Tamada, I.S. Kim, Manuka honey incorporated cellulose acetate nanofibrous mats: Fabrication and in vitro evaluation as a potential wound dressing, Int. J. Biol. Macromol. 155 (2020) 479489. https://doi.org/10.1016/j.ijbiomac.2020.03.237. 
[10] A. Ullah, Y. Saito, S. Ullah, M.K. Haider, H. Nawaz, P. Duy-Nam, D. Kharaghani, I.S. Kim, Bioactive Sambong oil-loaded electrospun cellulose acetate nanofibers: Preparation, characterization, and in-vitro biocompatibility, Int. J. Biol. Macromol. (2020). https://doi.org/10.1016/j.ijbiomac.2020.10.257.

[11] A. Zong, H. Cao, F. Wang, Anticancer polysaccharides from natural resources: a review of recent research., Carbohydr. Polym. 90 (2012) 1395-410. https://doi.org/10.1016/j.carbpol.2012.07.026.

[12] S.L. Flitsch, R. V Ulijn, Sugars tied to the spot, Nature. 421 (2016) 219-220. https://doi.org/10.1038/421219a.

[13] J.E. Ramberg, E.D. Nelson, R. a Sinnott, Immunomodulatory dietary polysaccharides: a systematic review of the literature., Nutr. J. 9 (2010) 54. https://doi.org/10.1186/1475-2891-9-54.

[14] R. Masood, T. Hussain, M. Miraftab, A. Ullah, Z.A. Raza, T. Areeb, M. Umar, Novel alginate, chitosan, and psyllium composite fiber for wound-care applications, J. Ind. Text. 47 (2017) 20-37. https://doi.org/10.1177/1528083716632805.

[15] K.I. Draget, C. Taylor, Chemical, physical and biological properties of alginates and their biomedical implications, Food Hydrocoll. 25 (2011) 251-256. https://doi.org/10.1016/j.foodhyd.2009.10.007.

[16] Y. Qin, The Characterization of Alginate Wound Dressings with Different Fiber and Textile Structures, J. Appl. Polym. Sci. 100 (2006) 2516-2520. https://doi.org/10.1002/app.23668.

[17] R. Masood, T. Hussain, M. Miraftab, Z. Ali Raza, A. Ullah, T. Areeb, M. Umar, R. Riaz, Development of tri-component antibacterial hybrid fibres for potential use in 
wound care, J. Wound Care. 27 (2018) 394-402.

https://doi.org/10.12968/jowc.2018.27.6.394.

[18] K. Yong, D.J. Mooney, Alginate : Properties and biomedical applications, Prog. Polym. Sci. 37 (2012) 106-126. https://doi.org/10.1016/j.progpolymsci.2011.06.003.

[19] T. Hussain, R. Masood, M. Umar, T. Areeb, A. Ullah, Development and characterization of alginate-chitosan-hyaluronic acid $(\mathrm{ACH})$ composite fibers for medical applications, Fibers Polym. 17 (2016) 1749-1756. https://doi.org/10.1007/s12221-016-6487-7.

[20] S. Vasvani, P. Kulkarni, D. Rawtani, Hyaluronic acid: A review on its biology, aspects of drug delivery, route of administrations and a special emphasis on its approved marketed products and recent clinical studies, Int. J. Biol. Macromol. (2019). https://doi.org/10.1016/j.ijbiomac.2019.11.066.

[21] A. La Gatta, R. Salzillo, C. Catalano, A.V.A. Pirozzi, A. D’Agostino, E. Bedini, M. Cammarota, M. De Rosa, C. Schiraldi, Hyaluronan-based hydrogels via ethercrosslinking: Is HA molecular weight an effective means to tune gel performance?, Int. J. Biol. Macromol. 144 (2020) 94-101. https://doi.org/10.1016/j.ijbiomac.2019.11.227.

[22] Y. Ji, K. Ghosh, X. Zheng, B. Li, J.C. Sokolov, G.D. Prestwich, R.A.F. Clark, M.H. Rafailovich, Electrospun three-dimensional hyaluronic acid nanofibrous scaffolds, Biomaterials. 27 (2006) 3782-3792. https://doi.org/10.1016/j.biomaterials.2006.02.037.

[23] C. Jou, L. Yuan, S. Lin, M. Hwang, W. Chou, D. Yu, M. Yang, Biocompatibility and antibacterial activity of chitosan and hyaluronic acid immobilized polyester fibers, J. Appl. Polym. Sci. 104 (2006) 16-21. https://doi.org/10.1002/app. 
[24] S. Garantziotis, R.C. Savani, Hyaluronan biology: A complex balancing act of structure, function, location and context, Matrix Biol. 78-79 (2019) 1-10. https://doi.org/10.1016/j.matbio.2019.02.002.

[25] S. Yamane, N. Iwasaki, T. Majima, T. Funakoshi, Feasibility of chitosan-based hyaluronic acid hybrid biomaterial for a novel scaffold in cartilage tissue engineering, Biomaterials. 26 (2005) 611-619. https://doi.org/10.1016/j.biomaterials.2004.03.013.

[26] N. Maeda, J. Miao, T.J. Simmons, J.S. Dordick, R.J. Linhardt, Composite polysaccharide fibers prepared by electrospinning and coating, Carbohydr. Polym. 102 (2013) 950-955. https://doi.org/10.1016/j.carbpol.2013.10.038.

[27] S. Yamane, N. Iwasaki, Y. Kasahara, K. Harada, T. Majima, K. Monde, S. Nishimura, A. Minami, Effect of pore size on in vitro cartilage formation using chitosan-based hyaluronic acid hybrid polymer fibers, J. Biomed. Mater. Res. Part A. 81 (2006) 586593. https://doi.org/10.1002/jbm.a.

[28] J.-M. Song, J.-H. Im, J.-H. Kang, D.-J. Kang, A simple method for hyaluronic acid quantification in culture broth, Carbohydr. Polym. 78 (2009) 633-634. https://doi.org/10.1016/j.carbpol.2009.04.033.

[29] F. Nicola, Turbidimetric measurement of acid mucopolysaccharides and hyaluronidase activity, J. Biol. Chem. (1955) 303-307.

[30] T. Hussain, A. Ullah, M. Umar, T. Areeb, Z. Zubair, R. Masood, Q. Zia, Modelling the properties of pigment-printed polypropylene nonwoven fabric using the Box-Behnken technique, Color. Technol. 131 (2015) 474-480. https://doi.org/10.1111/cote.12178.

[31] A. Ullah, S. Ullah, T. Areeb, M. Umar, P.D. Nam, R. Masood, S. Park, I.S. Kim, An Experimental Study on Modelling the Physical Properties of Composite Psyllium, 
Alginate and Chitosan Fibers Using Box-Behnken Technique, Fibers Polym. 21 (2020) 2494-2504. https://doi.org/DOI 10.1007/s12221-020-1277-7.

[32] J. Nastaj, A. Przewłocka, M. Rajkowska-Myśliwiec, Biosorption of Ni(II), Pb(II) and $\mathrm{Zn}(\mathrm{II})$ on calcium alginate beads: Equilibrium, kinetic and mechanism studies, Polish J. Chem. Technol. 18 (2016) 81-87. https://doi.org/10.1515/pjct-2016-0052.

[33] B.C. Silva, S. Alves, D. Oliveira, B. Campos, I.C. Riegel-vidotti, A. Urbano, P. Cristina, D.S. Faria-tischer, C. Augusto, Production and characterization of bacterial cellulose membranes with hyaluronic acid from chicken comb International Journal of Biological Macromolecules Production and characterization of bacterial cellulose membranes with hyaluronic acid from chicken c, Int. J. Biol. Macromol. 97 (2017) 642-653. https://doi.org/10.1016/j.ijbiomac.2017.01.077.

[34] J. Carneiro, P.M. Döll-boscardin, B.C. Fiorin, J. Mendes, P.V. Farago, J.P. De Paula, Development and characterization of hyaluronic acid-lysine nanoparticles with potential as innovative dermal filling, Brazilian J. Pharm. Sci. 52 (2016) 645-651. https://doi.org/http://dx.doi.org/10.1590/S1984-82502016000400008 Article Development.

[35] G. Xueping, L. School, W. Chunxi, Y. Guilan, Method for preparing calcium hyauronate, CN1326883 C, 2007.

[36] J. Necas, L. Bartosikova, P. Brauner, J. Kolar, Hyaluronic acid ( hyaluronan ): a review, Vet. Med. (Praha). 53 (2008) 397-411.

[37] N. Chunxue, Method for preparing transparent calcium hyaIuronate in low molecular weight, CN1563108 A, 2005.

[38] B. Sarker, R. Singh, R. Silva, J.A. Roether, J. Kaschta, R. Detsch, D.W. Schubert, I. 
Cicha, A.R. Boccaccini, Evaluation of fibroblasts adhesion and proliferation on alginate-gelatin crosslinked hydrogel, PLoS One. 9 (2014) 1-12. https://doi.org/10.1371/journal.pone.0107952.

[39] L.L. Bolton, C.L. Johnson, L. Van Rijswijk, Occlusive dressings: Therapeutic agents and effects on drug delivery, Clin. Dermatol. 9 (1991) 573-583. https://doi.org/10.1016/0738-081X(91)90087-2.

[40] Y. Yang, H. Hu, Application of superabsorbent spacer fabrics as exuding wound dressing, Polymers (Basel). 10 (2018). https://doi.org/10.3390/polym10020210. 


\section{List of Figures}

Fig. 1. An illustration of wet extruder machine and methods (a) and (b) used for AHA fiber production.

Fig. 2. Fitted line plot and quadratic equation for hyaluronic acid release at $600 \mathrm{~nm}$.

Fig. 3. SEM micrographs of the $S 1$ (a, a'), S2 (b, b'), S3 (c, c'), S4 (d, d'), S5 (e, e'), S6 (f, f'), and S7 (g, g') showing surface striations.

Fig. 4. ATR-FTIR spectra of the Hyaluronic acid, Sodium Alginate, and composite AHA fibers.

Fig. 5. Linear density (a) and tenacity (b) of the developed AHA fibers and control alginate fiber.

Fig. 6. Swelling percentage (a) and absorption capacity (b) of the developed AHA fibers, control alginate fiber (S7), and Dimora.

Fig. 7. Release of hyaluronic acid from the composite AHA fibers after 2 hours.

Fig. 8. Cell viability of nHDF cell line by mitochondrial activity using WST-1 assay, cultured for 1, 3, and 7 days in presence of AHA fibers, control alginate fiber (S7), and Dimora commercial sample.

Fig. 9. Cell attachment of nHDF cells cultured for $48 \mathrm{~h}$ in presence of AHA fibers $\mathrm{S} 1$ (a), S2(b), S3(c), S4(d), S5(e), S6(f), and control alginate fiber S7(g).

Fig. 10. Moisture vapor transport rate (MVTR) of Dimora, AHA composite and Alginate control fiber (S7). 


\section{List of Tables}

Table 1. Experimental design for alginate-hyaluronic acid fibers production.

Table 2. ANOVA for responses with respect to hyaluronic acid content. 
(a)

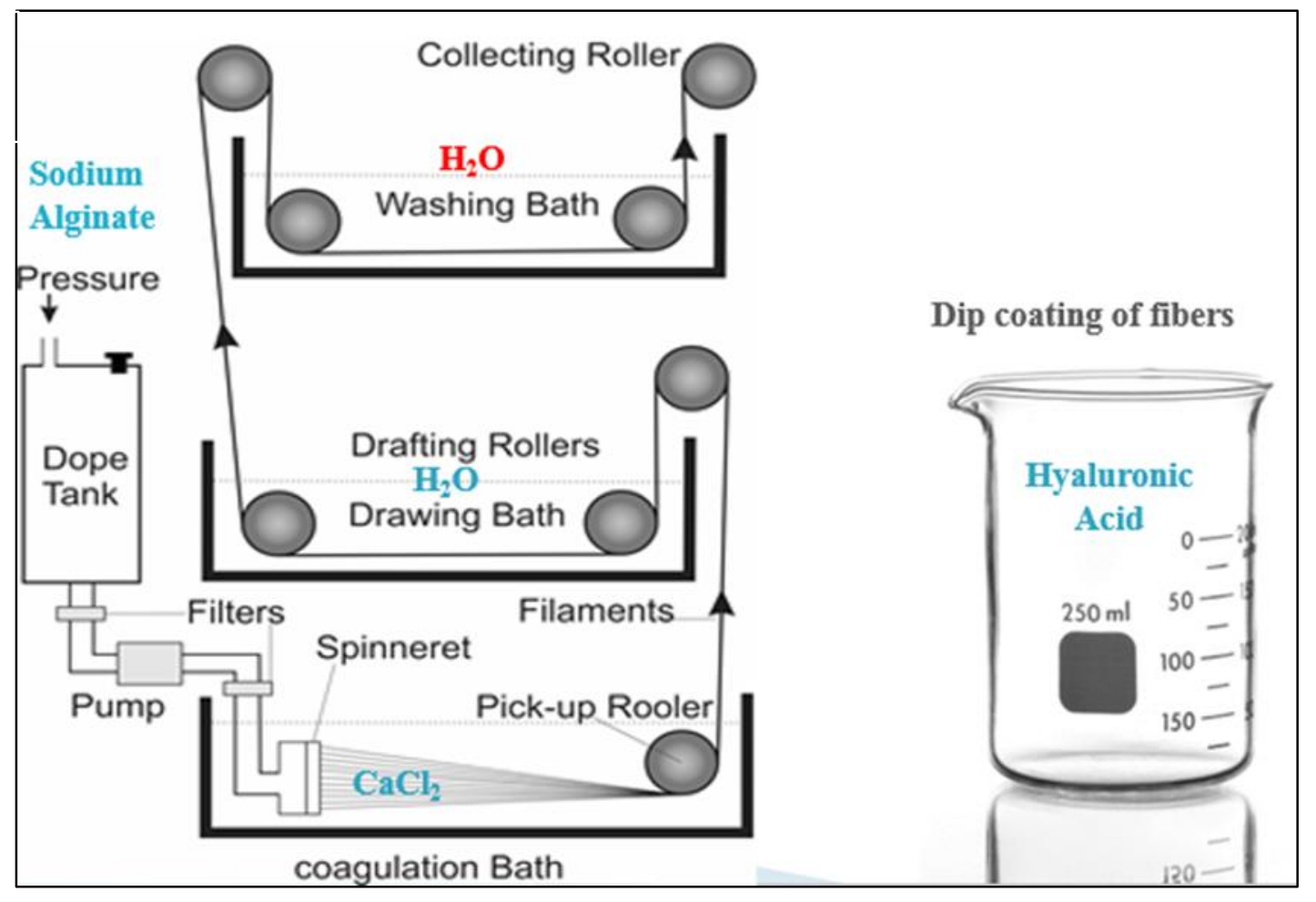

(b)

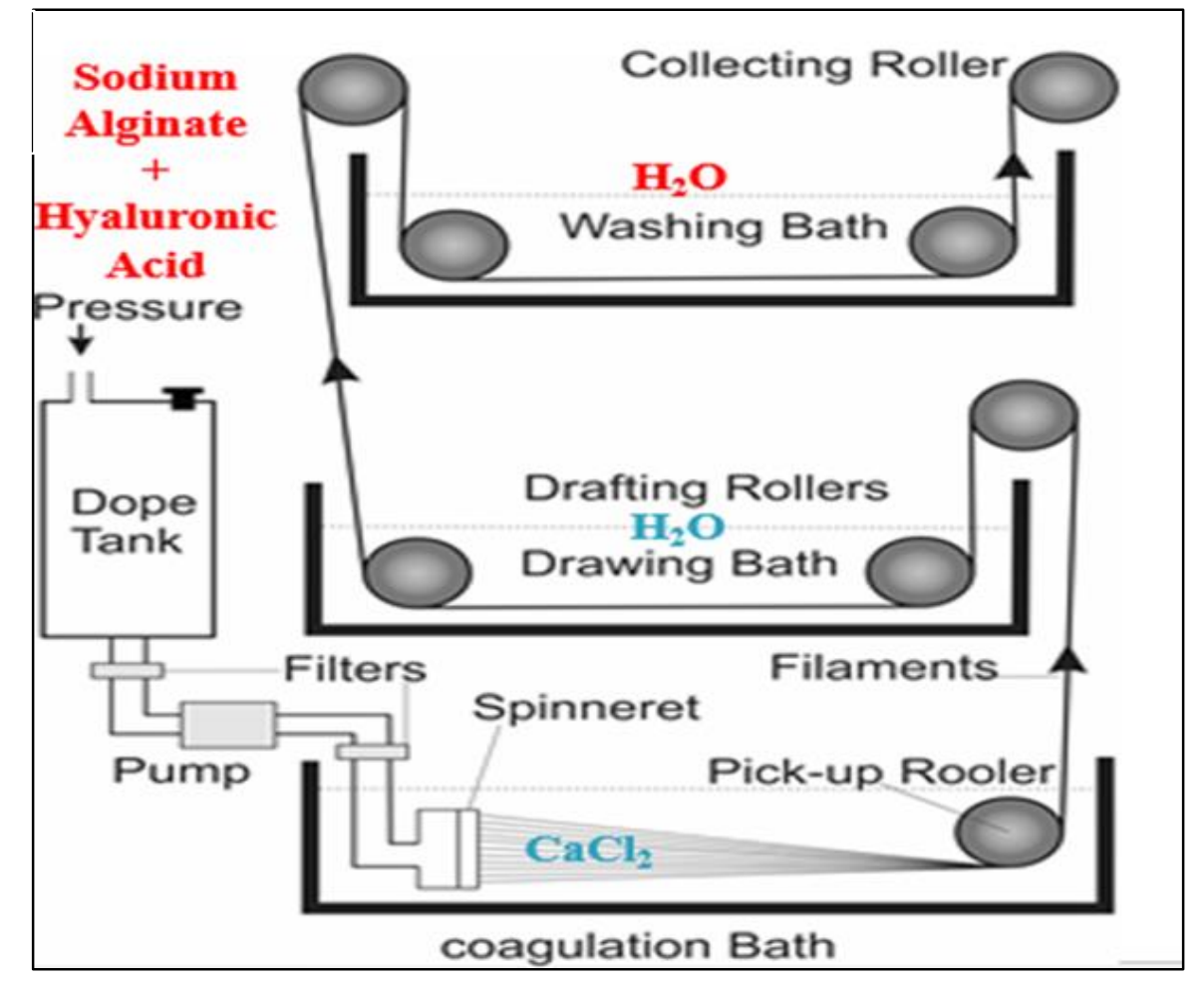

Fig. 1. An illustration of wet extruder machine and methods (a) and (b) used for AHA fiber production. 


\section{Fitted Line Plot}

$\mathrm{HA}$ ppm $=37.72-2.8 \mathrm{Abs}$

$$
+944.5 \mathrm{Abs}^{\wedge} 2
$$

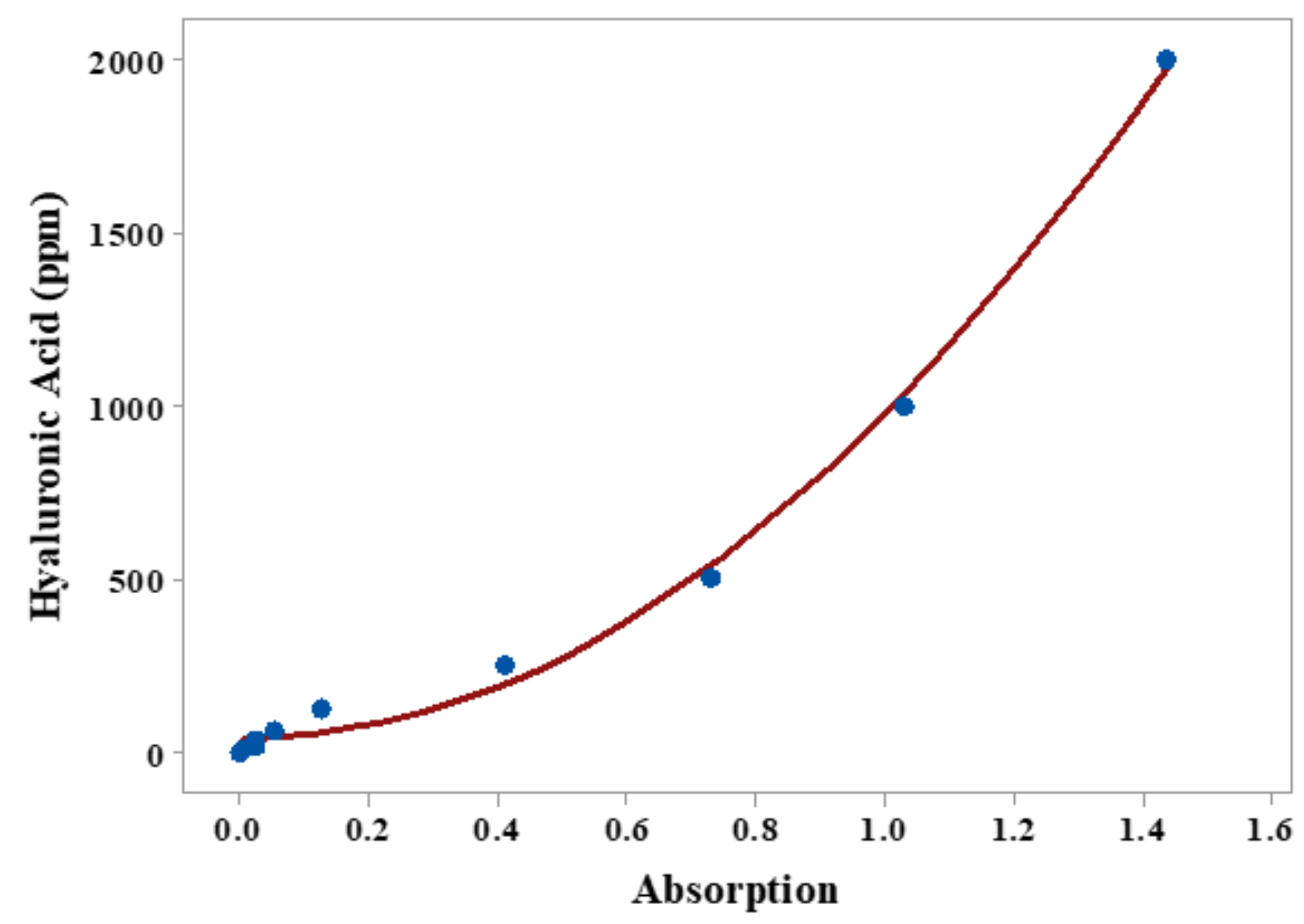

Fig. 2. Fitted line plot and quadratic equation for hyaluronic acid release at $600 \mathrm{~nm}$. 

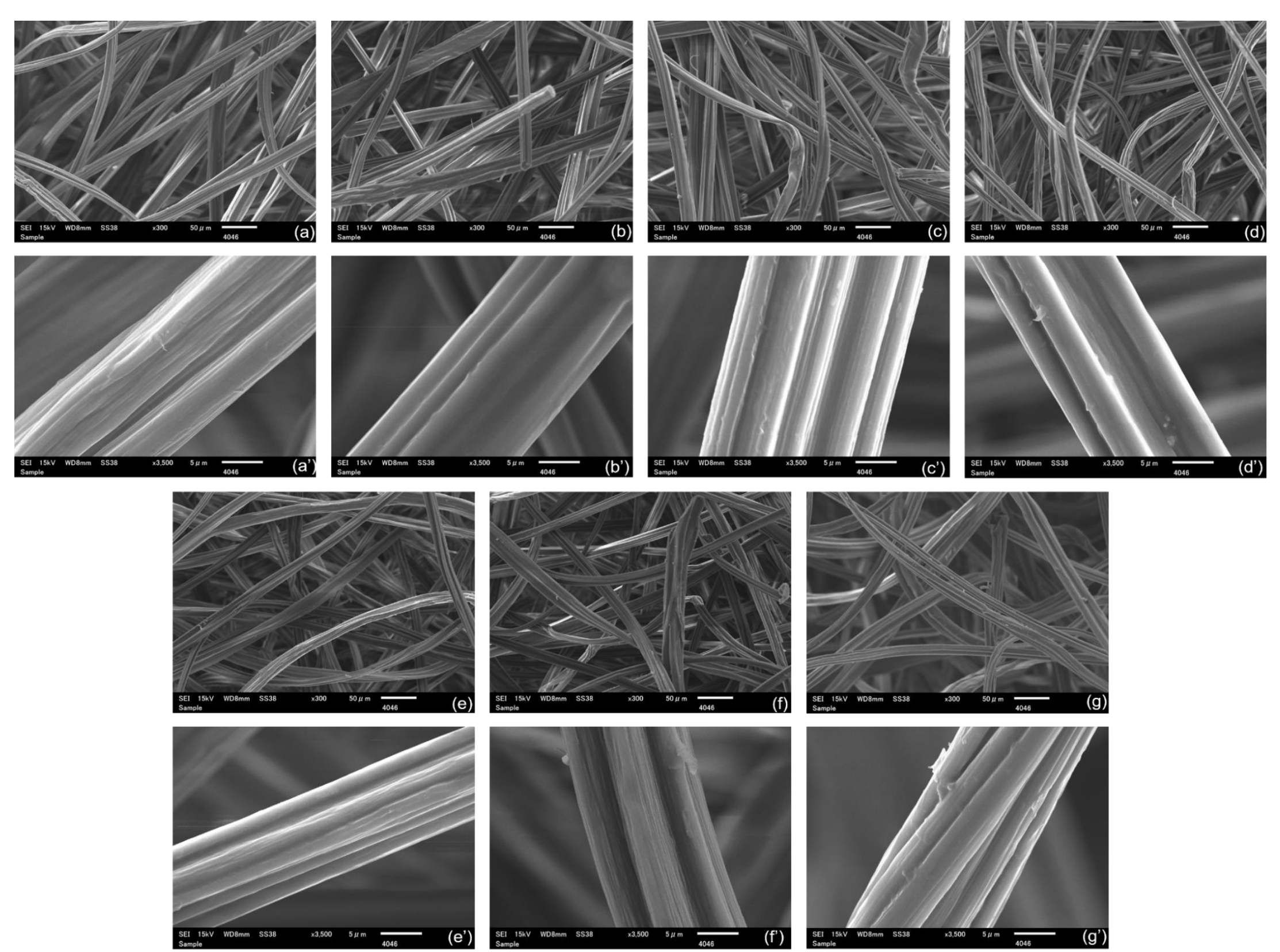

Fig. 3. SEM micrographs of the S1 (a, a'), S2 (b, b'), S3 (c, c'), S4 (d, d'), S5 (e, e'), S6 (f, f'), and S7 (g, g') showing surface striations. 


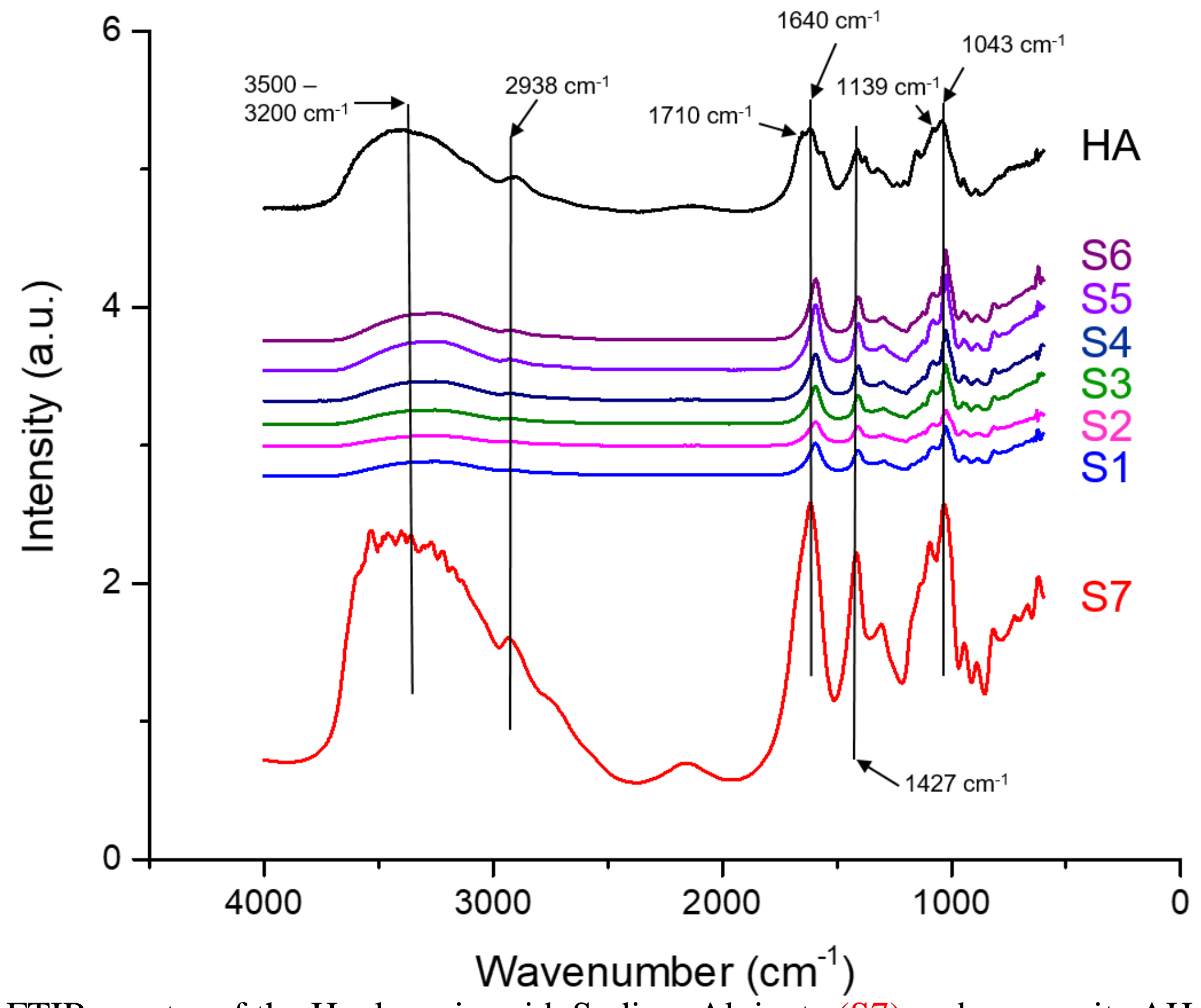

Fig. 4. ATR-FTIR spectra of the Hyaluronic acid, Sodium Alginate (S7) and composite AHA fibers. 

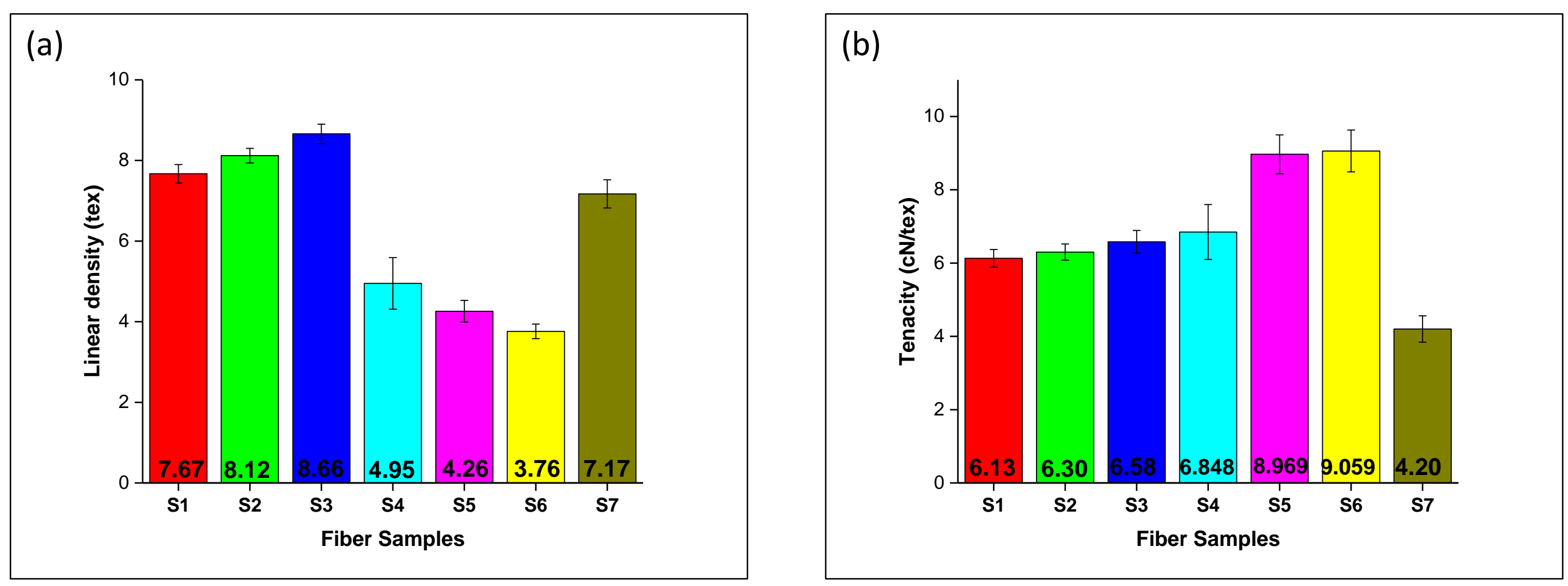

Fig. 5. Linear density (a) and tenacity (b) of the developed AHA fibers and control alginate fiber. 

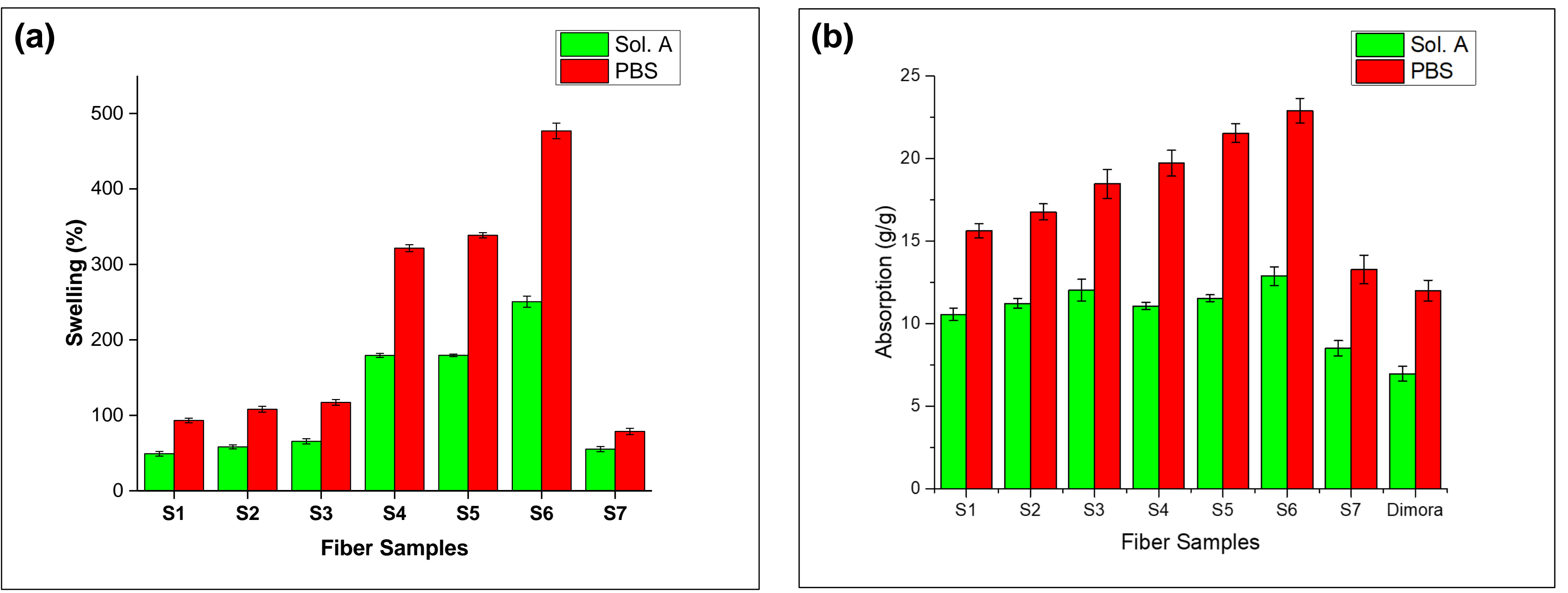

Fig. 6. Swelling percentage (a) and absorption capacity (b) of the developed AHA fibers and control alginate fiber (S7). 


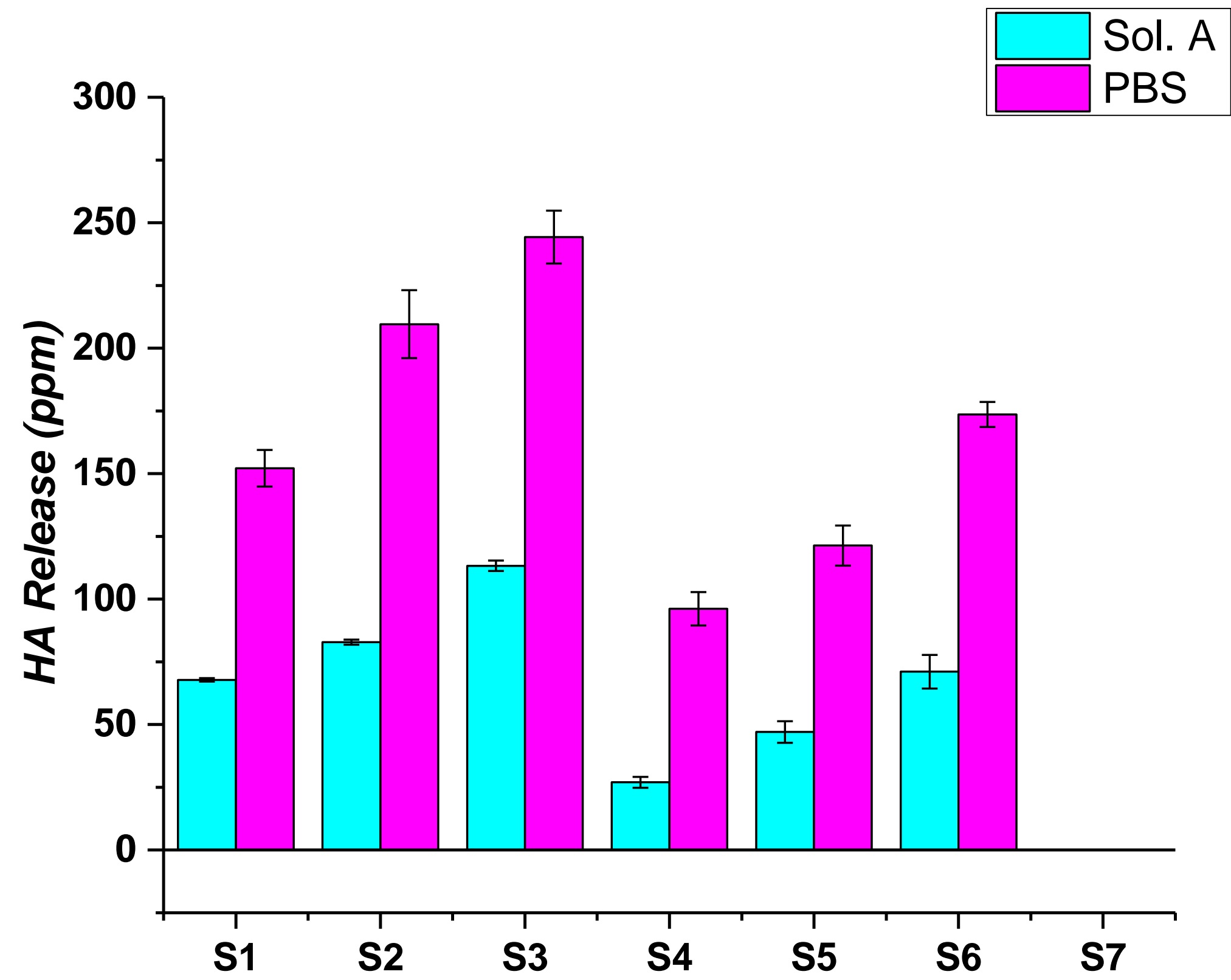

Fig. 7. Release of hyaluronic acid from the composite AHA fibers after 2 hours. 


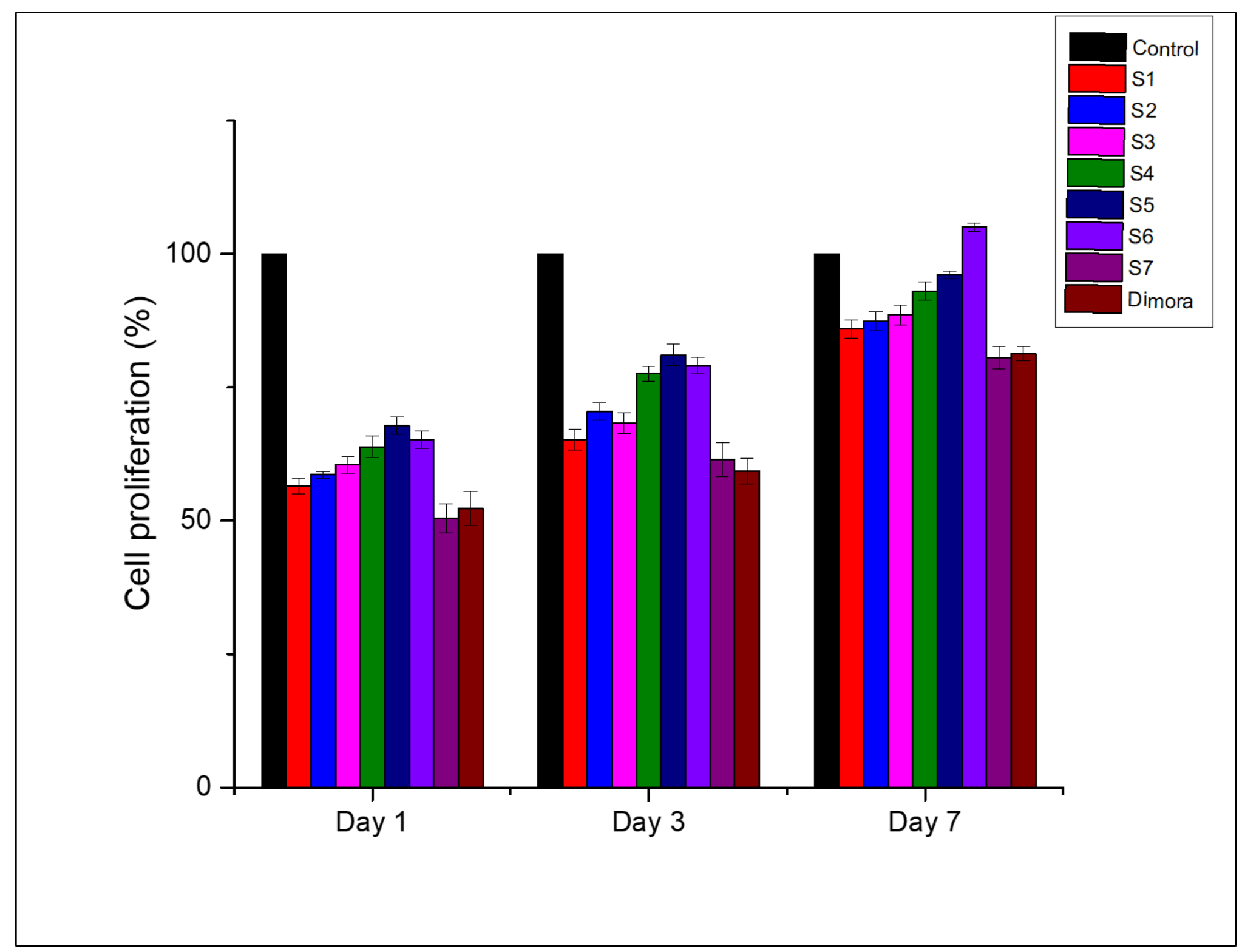

Fig. 8. Cell viability of nHDF cell line by mitochondrial activity using WST-1 assay, cultured for 1, 3, and 7 days in presence of AHA fibers, control alginate fiber (S7), and Dimora commercial sample. 

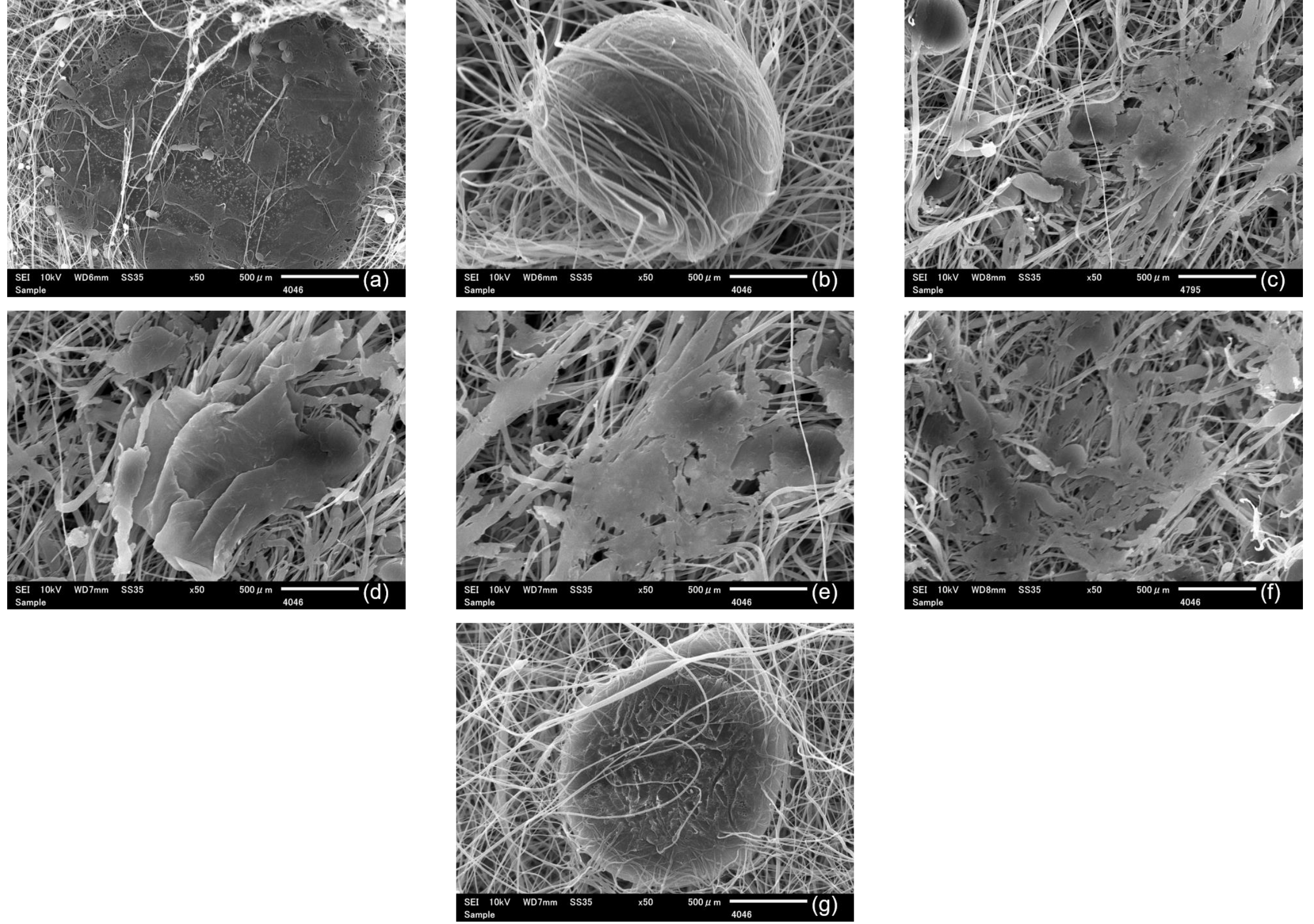

Fig. 9. Cell attachment of nHDF cells cultured for $48 \mathrm{~h}$ in presence of AHA fibers $\mathrm{S} 1(\mathrm{a}), \mathrm{S} 2(\mathrm{~b}), \mathrm{S} 3(\mathrm{c}), \mathrm{S} 4(\mathrm{~d}), \mathrm{S} 5(\mathrm{e}), \mathrm{S} 6(\mathrm{f})$, and control alginate fiber $S 7(\mathrm{~g})$. 
Table 1. Experimental design for alginate-hyaluronic acid fibers production.

\begin{tabular}{|c|c|c|c|c|c|}
\hline Sample Symbol & $\begin{array}{c}\text { Sodium } \\
\text { Alginate (\%) }\end{array}$ & $\begin{array}{c}\text { Hyaluronic } \\
\text { Acid (\%) }\end{array}$ & Drawing Ratio & $\begin{array}{c}\text { Dope Solution } \\
\text { Viscosity (cP) }\end{array}$ & $\begin{array}{c}\text { Coagulation } \\
\text { bath } \\
\text { (CaC12) (\%) }\end{array}$ \\
\hline \multicolumn{5}{|l|}{ Fiber Produced by First Route } \\
\hline S1 & 5.0 & 0.25 & 5.0 & 5500 & 1.5 \\
\hline S2 & 5.0 & 0.5 & 5.0 & 5500 & 1.5 \\
\hline S3 & 5.0 & 1.0 & 5.0 & 5500 & 1.5 \\
\hline Fiber Produced by Second Route & 5.0 & 0.25 & 5.0 & 6250 & 1.5 \\
\hline S4 & 5.0 & 0.5 & 5.0 & 6900 & 1.5 \\
\hline S5 & 5.0 & 1 & 5.0 & 7850 & 1.5 \\
\hline S6 & 5.0 & 0 & 5.0 & 5500 & 1.5 \\
\hline S7* & \multicolumn{5}{l}{} \\
\hline
\end{tabular}

*control fiber 
Table 2. ANOVA for responses with respect to hyaluronic acid content.

\begin{tabular}{|c|c|c|c|c|c|c|c|c|c|c|c|c|}
\hline \multirow[t]{3}{*}{ Factors } & \multirow{2}{*}{\multicolumn{2}{|c|}{ Linear density (tex) }} & \multirow{2}{*}{\multicolumn{2}{|c|}{ Tenacity (cN/tex) }} & \multicolumn{4}{|c|}{ Swelling (\%) } & \multicolumn{4}{|c|}{ Absorbance (\%) } \\
\hline & & & & & \multicolumn{2}{|c|}{ Sol. A } & \multicolumn{2}{|c|}{ PBS } & \multicolumn{2}{|c|}{ Sol. A } & \multicolumn{2}{|c|}{ PBS } \\
\hline & P-value & $\mathrm{R}^{2}(\%)$ & P-value & $R^{2}(\%)$ & P-value & $\mathrm{R}^{2}(\%)$ & P-value & $\mathrm{R}^{2}(\%)$ & P-value & $\mathbf{R}^{2}(\%)$ & P-value & $\mathrm{R}^{2}(\%)$ \\
\hline $\begin{array}{l}\text { Hyaluronic } \\
\text { Acid (dip } \\
\text { coating) }\end{array}$ & $0.000^{*}$ & 94.53 & $0.000^{*}$ & 98.42 & $0.000^{*}$ & 90.66 & $0.007^{*}$ & 96.04 & $0.000^{*}$ & 97.21 & $0.000^{*}$ & 95.21 \\
\hline $\begin{array}{c}\text { Hyaluronic } \\
\text { Acid (dope } \\
\text { mixture) }\end{array}$ & $0000^{*}$ & 98.34 & $0.000^{*}$ & 96.78 & $0.003^{*}$ & 89.34 & $0.000^{*}$ & 87.27 & $0.000^{*}$ & 91.37 & $0.000^{*}$ & 89.93 \\
\hline
\end{tabular}

$*$ P-value $<0.05$ indicating statistical significance of the factor to response under study, $\mathrm{R}^{2}$ coefficient of determination. 


\section{Author's Contribution Statement:}

Azeem Ullah: Conceptualization, Methodology, Writing - Original Draft, Investigation, Visualization, Data Curation, Writing - review \& editing.

Muhammad Umar: Conceptualization, Methodology, Investigation, Data Curation.

Hifza Nawaz: Formal analysis.

Tanzeel Areeb: Visualization, Formal analysis.

Motahira Hashmi: Formal analysis

Davood Kharaghani: Resource and Formal analysis.

Kyu Oh Kim: Resource

Ick Soo Kim: Validation, Supervisor. 